\title{
The Effects of the Honey-Roasting Process on the Pharmacokinetics of the Six Active Compounds of Licorice
}

\author{
Yulong Zhang, ${ }^{1,2}$ Mengyue Wang, ${ }^{1}$ Jingyu Yang, ${ }^{2}$ and Xiaobo Li $\mathbb{D}^{1}$ \\ ${ }^{1}$ School of Pharmacy, Shanghai Jiao Tong University, Shanghai, China \\ ${ }^{2}$ College of Traditional Chinese Materia Medica, Shenyang Pharmaceutical University, Shenyang, China \\ Correspondence should be addressed to Xiaobo Li; xbli@sjtu.edu.cn
}

Received 4 January 2018; Revised 3 April 2018; Accepted 31 May 2018; Published 21 June 2018

Academic Editor: Ciara Hughes

Copyright (c) 2018 Yulong Zhang et al. This is an open access article distributed under the Creative Commons Attribution License, which permits unrestricted use, distribution, and reproduction in any medium, provided the original work is properly cited.

\begin{abstract}
A convenient UPLC-MS/MS method was established to determine the contents of six bioactive compounds, namely, liquiritin apioside, liquiritin, isoliquiritin, liquiritigenin, isoliquiritigenin, and glycyrrhetinic acid, in rat plasma and their pharmacokinetics. By comparing the pharmacokinetic parameters of these compounds in rats by orally administering raw and honey-roasting licorice, the $\mathrm{C}_{\max }$ of isoliquiritin showed a significant decrease, while the $\mathrm{AUC}_{0-24 \mathrm{~h}}$ showed no significant differences. The $\mathrm{C}_{\max }$ and $\mathrm{AUC}_{0-24 \mathrm{~h}}$ of isoliquiritigenin were increased by $49.3 \%$ and $42.7 \%$ over those of the raw licorice group, respectively. These results indicate that the absorption of isoliquiritin in rats was reduced while the absorption of isoliquiritigenin was promoted in the honeyroasting process. These results may provide one explanation as to why licorice is more able to relieve cough, while honey-roasting licorice is better at invigorating $q i$ and restoring pulse. Furthermore, the $\mathrm{C}_{\max }$ of glycyrrhetinic acid was increased, suggesting that it may enhance the tonic effect of licorice. Additionally, the amount of honey added in the honey-roasting process influenced the pharmacokinetic parameters of the six compounds whose absorption decreased when the 50\% honey-roasting licorice water decoction was administered. These results provide an experimental basis for studying the influence of licorice processing on bioactive compound pharmacokinetics.
\end{abstract}

\section{Introduction}

Licorice, Gancao in Chinese, is a commonly used traditional Chinese medicine (TCM) and is frequently divided into raw Gancao (Glycyrrhizae Radix et Rhizoma) and Zhi-gancao (Glycyrrhizae Radix et Rhizoma Praeparata Cum Melle) in TCM formularies. Zhi-gancao is produced by a method in which raw Gancao is stir-fried with honey until it becomes yellow to deep yellow and not sticky and is then cooled in the air [1]. The uses of raw licorice could reinforce the function of the spleen, dispel phlegm, relieve cough, and moderate the properties of other herbs; however, Zhigancao is used to invigorate the functions of spleen and stomach as well as to reinforce $q i$ and promote blood circulation [1]. It was reported that honey-roasting licorice (Zhigancao) also has better anti-inflammatory $[2,3]$, neuroprotective [4], and immunity-enhancing [5] properties than raw licorice.
Chemical and pharmaceutical studies showed that triterpene saponins and flavonoids $[6,7]$ are the main bioactive compounds in licorice. Liquiritin can stimulate immune responses and activate antioxidant enzymes [8]; liquiritigenin and isoliquiritigenin display PPAP $\gamma$ activating activity, suggesting their potential as a treatment of metabolic syndrome [9]. Moreover, glycyrrhetinic acid, a metabolic product of glycyrrhizic acid [10], was reported to have positive effects on the protection of rat hepatocytes [11] and the inhibition of inflammation [12].

A great deal of research has focused on the pharmacological effects of raw and honey-roasting licorice. The different processing technologies are associated with variations in the chemical constituents of licorice [13]. We have shown that after honey-roasting, the contents of the effective chemical components varied, with lessening of the decocting quantity of liquiritin apioside and liquiritin and increase in isoliquiritin [14-16]. The pharmacokinetic parameters of bioactive 
flavones were detected in rat plasma after oral administration of flavone-enriched raw licorice [17]. Few studies on the pharmacokinetic profiles of the honey-roasting licorice have been performed. Hence, after oral administration of honey-roasting licorice, to detect bioactive compounds in rat plasma and their pharmacokinetic behaviors is worth studying to explain the medicinal principles which are responsible for the pharmacological effects of honey-roasting licorice.

Therefore, this study aims to compare the pharmacokinetics of liquiritin apioside, liquiritin, isoliquiritin, liquiritigenin, isoliquiritigenin, and glycyrrhetic acid in rats after oral administration of raw/honey-roasting licorice. The results of this study provide helpful information to facilitate the clinical application and processing technology of honeyroasting licorice.

\section{Materials and Methods}

2.1. Chemicals and Reagents. HPLC grade acetonitrile was purchased from Merck Company (Darmstadt, Germany). Ultrapure water for the UPLC mobile phase was prepared using a Milli-Q purification system (Millipore, Bedford, MA, USA). Raw licorice slices were purchased from Yili Science and Technology Industry Co., Ltd. (Inner Mongolia, China). Honey was purchased from Jingan Pharmaceutical Co., Ltd. (Shanghai, China). Honey-roasting licorice slices were prepared in the lab (the details of the experiment are given in Licorice Processing and Decoction). The reference standards of liquiritin apioside (LA), liquiritin (LQ), isoliquiritin (ILQ), liquiritigenin (LG), isoliquiritigenin (ILG), glycyrrhetinic acid (GA), and andrographolide (internal standard, IS) were purchased from Sichuan Wekeqi Co., Ltd. (Sichuan, China). Other chemicals were of analytical grade.

2.2. Licorice Processing and Decoction. In accordance with the Chinese Pharmacopoeia Committee (2015), raw licorice slices (100 g for each) were stir-fried with $25 \mathrm{~g}$ of honey until they became yellow to deep yellow and were not sticky to the fingers. They were cooled in the air to yield $25 \%$ honey-roasting licorice $(\mathrm{w} / \mathrm{w})$ slices. With the same method, 50\% honey-roasting licorice (w/w) slices were prepared.

Raw licorice slices (100 g) were decocted twice in distilled water $(1000 \mathrm{~mL})$ for $30 \mathrm{~min}$. Water decoction of raw licorice was filtered and concentrated to $1.00 \mathrm{~g}$ (crude drug)/mL using a rotary evaporation apparatus. The 25\% honey-roasting licorice slices (100 g, equivalent to $87 \mathrm{~g}$ raw licorice) and $50 \%$ honey-roasting licorice slices (100 g, equivalent to $72 \mathrm{~g}$ raw licorice) were treated with the same method.

2.3. Animals. Healthy male Wistar rats (weighing $200 \pm 20$ g) were obtained from the Laboratory Animal Centre of Shanghai Jiao Tong University (Shanghai, China). The rats were kept in a temperature-controlled environment with free access to laboratory food and water for one week and were deprived of food for $12 \mathrm{~h}$ before the experiment. All protocols and procedures were approved by the Shanghai Jiao Tong University Animal Care and Use Committee.
2.4. Chromatographic and Mass Spectrometric Conditions. Quantification of LA, LQ, ILQ, LG, ILG, and GA was performed on a Waters UPLC system with an Applied Biosystem 5500 QTRAP ${ }^{\circledR}$ hybrid triple-quadrupole mass spectrometer (Applied Biosystems/MDS Sciex, Foster City, CA, USA), equipped with a turbo ion spray source. Chromatographic separation was performed on a ZORBAX Eclipse Plus C18 column $(50 \mathrm{~mm} \times 2.1 \mathrm{~mm}, 1.8 \mu \mathrm{m})$. The mobile phase consisted of $2 \mathrm{mM}$ ammonium acetate water (A) and acetonitrile (B) using a gradient elution of $10 \%-95 \%$ B at $0-4.0$ $\mathrm{min}, 95 \% \mathrm{~B}$ at $4.0-5.0 \mathrm{~min}, 95 \%-10 \% \mathrm{~B}$ at $5.0-5.1 \mathrm{~min}$, and $10 \% \mathrm{~B}$ at 5.1-7.0 $\mathrm{min}$. The flow rate was set at $0.4 \mathrm{~mL} / \mathrm{min}$. The column temperature and injection volume were set at $40^{\circ} \mathrm{C}$ and $2.0 \mu \mathrm{L}$, respectively. An MS system operating in negative electrospray ionization mode was employed in this study. Quantification was performed using a multiple reaction monitoring $(\mathrm{MRM})$ model of the transition $\mathrm{m} / z$ [M$\mathrm{H}{ }^{-} 549.2 \rightarrow 134.9$ for LA, $m / z[\mathrm{M}-\mathrm{H}]{ }^{-} 417.2 \rightarrow 118.9$ for $\mathrm{LQ}$, $m / z[\mathrm{M}-\mathrm{H}]^{-} \quad 417.1 \rightarrow 134.9$ for ILQ, $m / z$ [M-H] ${ }^{-} 255.1 \rightarrow 118.9$ for $\mathrm{LG}, m / z[\mathrm{M}-\mathrm{H}]{ }^{-} 255.2 \rightarrow 118.9$ for ILG, $m / z[\mathrm{M}-\mathrm{H}]$ $469.3 \rightarrow 355.3$ for $\mathrm{GA}$, and $m / z$ [M-H] ${ }^{-} 349.2 \rightarrow 287.1$ for IS. The DP for each compound and IS were -120, -100, -100, $100,-100,-80$, and $-100 \mathrm{~V}$, respectively. The collision energy for each compound and IS were $-58,-32,-42,-32,-32,-65$, and $-20 \mathrm{~V}$, respectively. The ion spray needle voltage was set at $-4500 \mathrm{~V}$, and the source temperature was $500^{\circ} \mathrm{C}$. Following optimization of the setting parameters, the ESI source was operated with the GS1, GS2, and CUR (Nitrogen) set at 35, 35 , and 40 psi, respectively.

2.5. Stock Solutions and Quality Control Samples. Standard stock solutions of LA, LQ, ILQ, LG, ILG, GA, and IS (1.00 $\mathrm{mg} / \mathrm{mL}$, respectively) were dissolved in acetonitrile. The working solutions for the calibration curve were diluted with $70 \%$ acetonitrile. The plasma samples for the calibration curve were prepared by spiking the above working solutions into blank plasma to yield the final concentration series: $4.75-800.00 \mathrm{ng} / \mathrm{mL}$ for LA, $0.83-500.00 \mathrm{ng} / \mathrm{mL}$ for LQ, $0.39-833.33 \mathrm{ng} / \mathrm{mL}$ for ILQ, $0.42-20.00 \mathrm{ng} / \mathrm{mL}$ for $\mathrm{LG}$, $0.17-500.00 \mathrm{ng} / \mathrm{mL}$ for ILG, and $2.37-500.00 \mathrm{ng} / \mathrm{mL}$ for GA.

The IS working solution was also diluted to a concentration of $10.00 \mu \mathrm{g} / \mathrm{mL}$ with $70 \%$ acetonitrile. The QC samples at three concentration levels-10.00, 100.00, and $500.00 \mathrm{ng} / \mathrm{mL}$ for $\mathrm{LA} ; 1.00,166.67$, and $333.33 \mathrm{ng} / \mathrm{mL}$ for LQ; $1.67,40.00$, and $500.00 \mathrm{ng} / \mathrm{mL}$ for ILQ; $0.84,10.00$, and $16.67 \mathrm{ng} / \mathrm{mL}$ for LG, $0.33,166.67$; and $333.33 \mathrm{ng} / \mathrm{mL}$ for ILG, 5.00, 10.00, and $100.00 \mathrm{ng} / \mathrm{mL}$ for GA (low, medium, and high levels, respectively)_-were prepared in blank plasma.

2.6. Sample Preparation. Fifty microliters of the plasma samples (or standard plasma samples and QC samples) were spiked with $5 \mu \mathrm{L}$ of IS solution $(10.00 \mu \mathrm{g} / \mathrm{mL})$ and 200 $\mu \mathrm{L}$ of acetonitrile. The mixture was vortexed for $30 \mathrm{~s}$ and centrifuged at $14,000 \mathrm{rpm}$ for $15 \mathrm{~min}$ at $4^{\circ} \mathrm{C}$. The supernatant was collected and evaporated in a $37^{\circ} \mathrm{C}$ water bath under a nitrogen stream. The residue was redissolved with $500 \mu \mathrm{L}$ of $70 \%$ acetonitrile. 
TABLE 1: Linear regression equation, linear range, and LLOQ of six compounds.

\begin{tabular}{lcccc}
\hline Compound & Linear Regression Equation & $\mathrm{r}^{2}$ & Linear range $(\mathrm{ng} / \mathrm{mL})$ & LLOQ $(\mathrm{ng} / \mathrm{mL})$ \\
\hline LA & $\mathrm{y}=0.1056 \mathrm{x}+0.2601$ & 0.9981 & $4.75-800.00$ & $0.83-500.00$ \\
LQ & $\mathrm{y}=0.0447 \mathrm{x}-0.1266$ & 0.9973 & $0.39-833.33$ & 0.83 \\
ILQ & $\mathrm{y}=6.6859 \mathrm{x}+1.256$ & 0.9988 & $0.42-20.00$ & 0.39 \\
LG & $\mathrm{y}=0.9577 \mathrm{x}-0.2405$ & 0.9952 & $0.17-500.00$ & 0.42 \\
ILG & $\mathrm{y}=5.3311 \mathrm{x}-0.6098$ & 0.9966 & $2.37-500.00$ & 0.17 \\
GA & $\mathrm{y}=6.0739 \mathrm{x}-1.9631$ & 0.9997 & & 2.37 \\
\hline
\end{tabular}

2.7. Method Validation. The method was validated for selectivity, linearity, lower limit of quantification, accuracy, precision, extraction recovery, and stability according to the US Food and Drug Administration Bioanalytical Method Validation Guide.

2.7.1. Selectivity. The selectivity of the method was investigated by comparing the chromatograms of the blank plasma sample; blank plasma sample spiked with LA, LQ, ILQ, LG, ILG, GA, and IS; and plasma sample after administration of the licorice decoction.

2.7.2. Linearity and Lower Limit of Quantification (LLOQ). The linear regression equation consisted of five concentration levels and was determined by plotting the ratio of the peak as of the compound to IS $(y)$ versus the concentration $(x)$ of the reference standard with a $1 / \mathrm{x}$-weighted least-square linear regression algorithm. The LLOQ was defined as the lowest concentration on the calibration curve ( determined with accuracy (expressed as relative error, RE) within $\pm 15 \%$ and precision (expressed as relative standard deviation, RSD) less than $15 \%$.

2.7.3. Accuracy and Precision. The intraday accuracy and precision of the method were assessed by six replicate analyses of QC samples at low, medium, or high concentrations on the same day. Similarly, the interday accuracy and precision were determined for three consecutive days. The intra- and interday accuracy were expressed as RE, and the precision was expressed as RSD.

2.7.4. Extraction Recovery and Matrix Effect. The extraction recovery of each analyte was calculated as extraction recovery $(\%)=$ (peak area of analyte spiked in blank sample $\times$ $100 /$ peak area of analyte spiked in postpreparative sample). The matrix effect was measured by comparing the peak areas of the postextracted standard plasma samples with $70 \%$ acetonitrile containing equivalent amounts of all the analytes.

2.7.5. Stability. The stabilities of the six compounds in rat plasma were evaluated by analyzing QC samples under different conditions. Short-term stability was tested by storing the postpreparative QC samples in the autosampler at $4^{\circ} \mathrm{C}$ for $24 \mathrm{~h}$. Long-term stability was tested by storing QC samples at $-80^{\circ} \mathrm{C}$ for one month. RSD was evaluated by analyzing six replicate samples.
2.8. Pharmacokinetic Study. After being housed in a controlled environment for a week, rats were randomly divided into three groups ( $\mathrm{n}=5$ for each group) and were then orally administered a raw, 25\% honey-roasting, or $50 \%$ honey-roasting licorice water decoction at a dosage of 2.7 g (crude drug) $/ \mathrm{kg}$. Blood samples of $0.15 \mathrm{~mL}$ were taken from the suborbital vein into heparinized tubes at $0.17,0.5$, $1,1.5,2,2.5,3,4,6,8,12$, and $24 \mathrm{~h}$ after oral administration of the licorice water decoction. The blood samples were immediately centrifuged at $10,000 \mathrm{rpm}$ for $15 \mathrm{~min}$. The separated plasma samples were frozen at $-80^{\circ} \mathrm{C}$ before analysis.

2.9. Statistical Analysis. The pharmacokinetic parameters of the six compounds were calculated by KINETICA 4.4.1 (Thermo Electron Corporation, Philadelphia, PA, USA) software. Noncompartmental analysis was used to determine the area under the curve $\left(\mathrm{AUC}_{0-24 \mathrm{~h}}\right)$, maximum plasma concentration $\left(\mathrm{C}_{\max }\right)$, and time to attain $\left(\mathrm{T}_{\max }\right)$. Data were presented as the mean \pm SD. Statistical analyses of all the data obtained were evaluated using one-way ANOVA (SPSS 17.0).

\section{Results and Discussion}

\subsection{Method Validation}

3.1.1. Selectivity. LA, LQ, ILQ, LG, ILG, and GA were identified in rat plasma by UPLC-MS after oral administration of raw/honey-roasting licorice. The selectivity of the method was determined by comparing representative chromatograms of blank rat plasma, blank rat plasma spiked with six reference standards (LA, LQ, ILQ, LG, ILG, and GA) and andrographolide, and plasma samples after oral administration of $25 \%$ honey-roasting licorice (Figure 1). It was shown that no interference was detected from endogenous substances and the background noise was low.

3.1.2. Linearity and Lower Limit of Quantification (LLOQ). The linear regression equations, linear ranges, and LLOQs of the six compounds are listed in Table 1 . The linear regression equations of all of the compounds exhibited good linearity with correlation coefficients $\left(r^{2}\right)>0.99$. The LLOQs for LA, LQ, ILQ, LG, ILG, and GA were appropriate for the quantitative detection of these compounds in pharmacokinetic studies. 


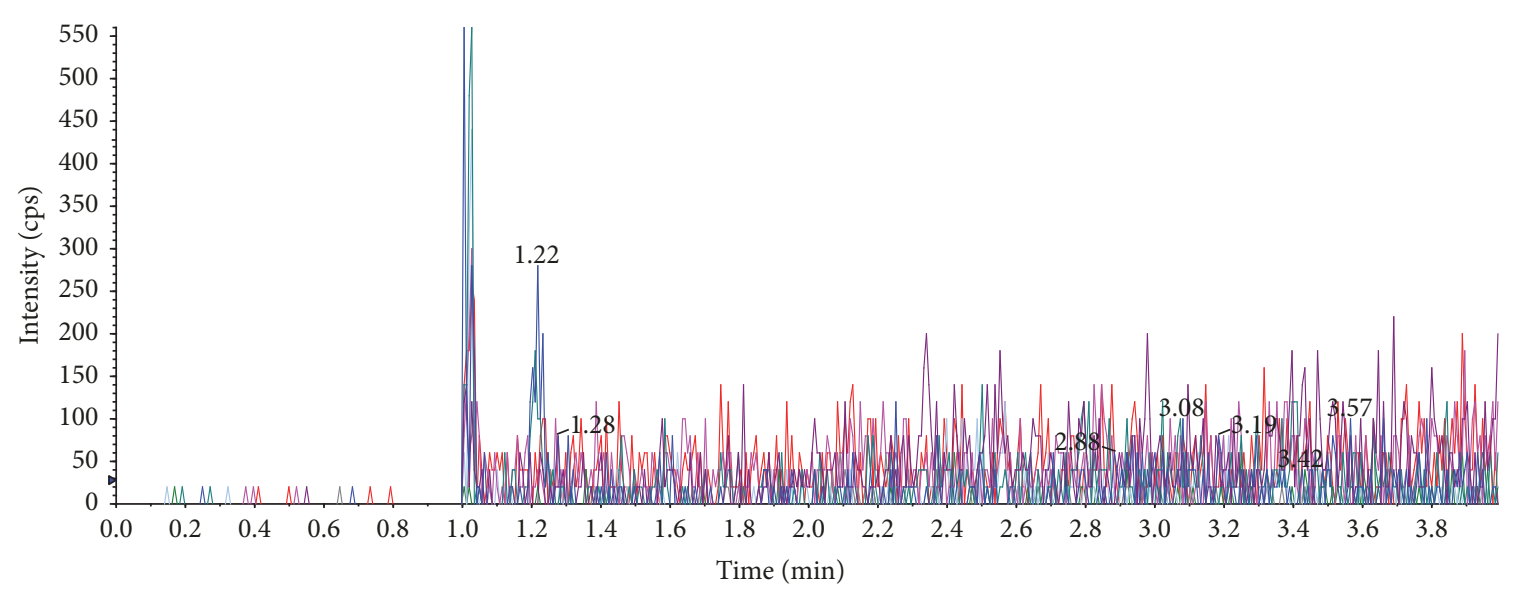

(a)

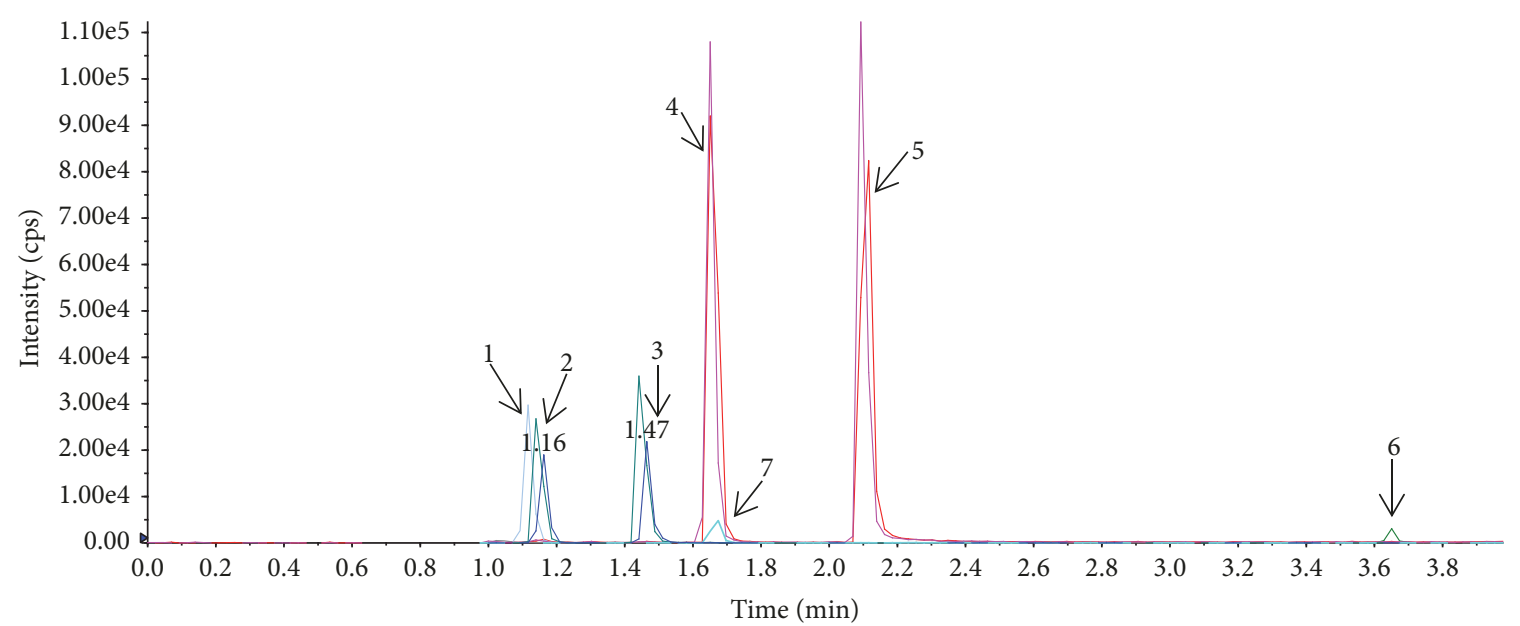

(b)

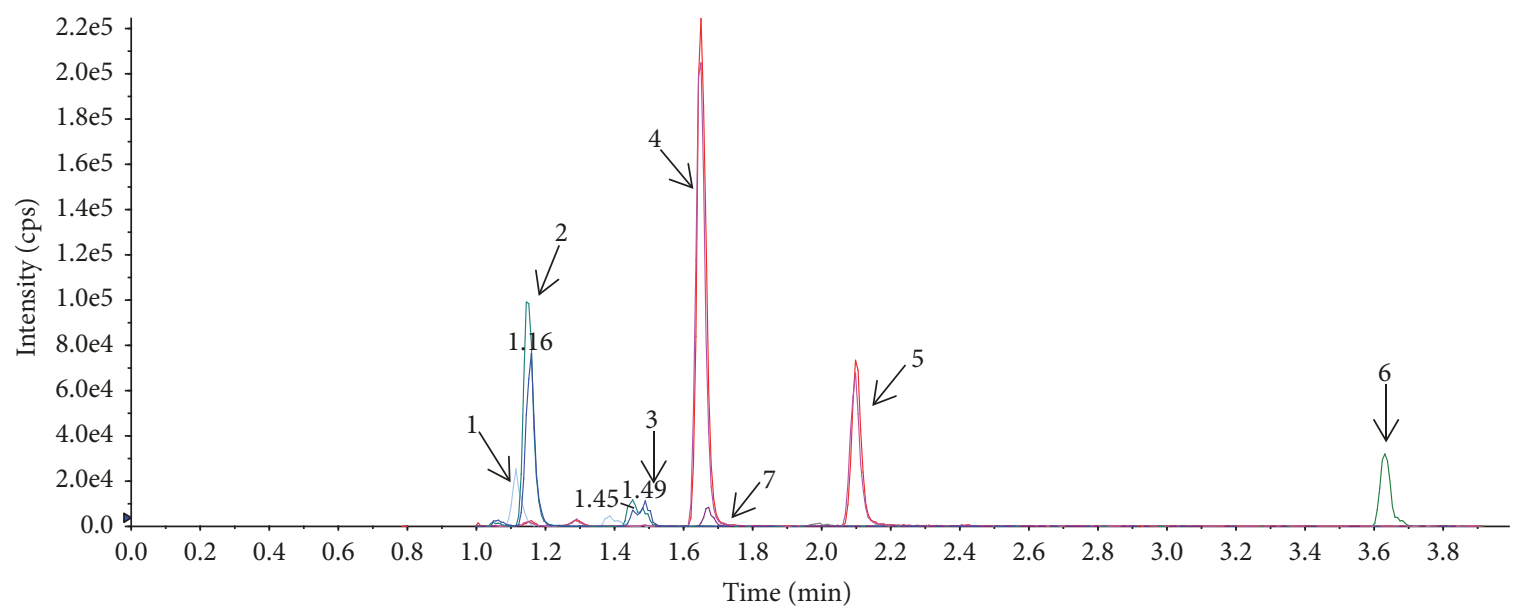

(c)

FIGURE 1: Representative MRM chromatograms of LA, LQ, ILQ, LG, GA, and IS in plasma: (a) blank plasma; (b) a blank plasma sample spiked with LA (100.00 ng/mL), LQ (166.67 ng/mL), ILQ (40.00 ng/mL), LG (16.67 ng/mL), ILG (166.67 ng/mL), GA (5.00 ng/mL) reference standard, and IS $(10.00 \mu \mathrm{g} / \mathrm{mL}) ;(\mathrm{c})$ and an actual plasma sample obtained from a rat at $2.5 \mathrm{~h}$ after oral administration of $25 \%$ honey-roasting licorice. 1 (LA), 2 (LQ), 3 (ILQ), 4 (LG), 5 (ILG), 6 (GA), 7 (IS). 
3.1.3. Precision and Accuracy. The precision and accuracy were determined to analyze the quality control (QC) samples at three concentration levels. The intraday precision $(n=6$, RSD\%) and accuracy $(\mathrm{n}=6, \mathrm{RE} \%)$ of the six compounds ranged from $2.8 \%$ to $10.5 \%$ and $85.1 \%$ to $103.6 \%$, respectively. The interday precision $(\mathrm{n}=6, \mathrm{RSD} \%)$ and accuracy $(\mathrm{n}=$ 6. RE\%) ranged from $3.9 \%$ to $12.4 \%$ and $86.2 \%$ to $102.3 \%$, respectively. The precision and accuracy data are summarized in Table 2. These results indicated that the method was reproducible and accurate for detecting the six compounds in rat plasma.

3.1.4. Extraction Recovery and Matrix Effect. The extraction recoveries of the six compounds at three QC concentration levels are shown in Table 2. These data indicated that the extraction efficiency of the method was within an acceptable range. The matrix effect values obtained for all analytes ranged from $101.1 \%$ to $109.1 \%$, and the matrix effect for IS was $104.3 \%$. The results suggested that the matrix effects for all analytes and IS were in acceptable range.

3.1.5. Stability. The stability of the six compounds was evaluated under various conditions. QC samples stored in a freezer at $-80^{\circ} \mathrm{C}$ remained stable for one month. QC samples after preparation in an autosampler $\left(4^{\circ} \mathrm{C}\right)$ for $24 \mathrm{~h}$ appeared to have no effect on the quantitation of the six compounds. The stability data were within the acceptance range of $85 \%$ $115 \%$ (Table 3). The results showed that, in rat plasma, the six compounds were stable before quantitation.

3.2. Comparative Pharmacokinetic Studies. The validated UPLC-MS/MS method was applied to the pharmacokinetic study of LA, LQ, ILQ, LG, ILG, and GA in rats after oral administration of a water decoction of raw or honeyroasting licorice. The concentration-time curves of the six compounds in rat plasma are shown in Figure 2, and the corresponding pharmacokinetic parameters are summarized in Table 4. Comparison of the pharmacokinetic parameters of five flavones in rats after oral administration of raw/honeyroasting licorice showed that the $\mathrm{C}_{\max }$ and $\mathrm{AUC}_{0-24 \mathrm{~h}}$ of LA, LQ, ILQ, and LG decreased in honey-roasting licorice. Additionally, the $\mathrm{C}_{\max }$ and $\mathrm{AUC}_{0-24 \mathrm{~h}}$ of $\mathrm{GA}$ were higher than those in raw licorice group, but there were no significant differences.

First, the $\mathrm{C}_{\max }$ of flavones was reduced in the honeyroasting groups; the $\mathrm{C}_{\max }$ of ILQ in the $25 \%$ honey-roasting group was $24.80 \pm 3.63 \mathrm{ng} / \mathrm{mL}$, which was $48.07 \%$ lower than that in the raw group. Additionally, $\mathrm{T}_{\max }$ was 1.75 times longer in 25\% honey-roasting group. However, there were no significant differences between the $25 \%$ honey-roasting and raw groups regarding $\mathrm{AUC}_{0-24 \mathrm{~h}}$. These results showed that ILQ was absorbed by rats more slowly after the honeyroasting treatment. Meanwhile, after processing with honey, the decocted contents of the main glycosides of licorice obviously changed. Our previous studies showed that the quantity of ILQ from water decoction of honey-roasting licorice was higher than that of licorice [14-16]. Thus, the honey-roasting process affected the pharmacokinetic behavior of ILQ, which can be antispasmodic [18] and antitussive [19]. These results provide supportive evidence that explains why raw licorice is more able to alleviate pain and relieve cough than honeyroasting licorice. While the $\mathrm{AUC}_{0-24 \mathrm{~h}}$ of ILG was significantly improved $(\mathrm{P}<0.05)$ from $6.53 \pm 2.34 \mathrm{~h} \cdot \mathrm{ng} / \mathrm{mL}$ to $9.32 \pm 0.68$ $\mathrm{h} \cdot \mathrm{ng} / \mathrm{mL}$ after licorice was processed with honey, the $\mathrm{C}_{\max }$ in the $25 \%$ honey-roasting group was $49.3 \%$ higher than that in raw group for ILG. Additionally, ILG was reported to have an antiplatelet effect [20] and an accumulation of cAMP [21]. This suggested that ILG could alleviate symptoms, such as insufficiency of the spleen and deficiency of $q i$ and blood, by increasing the accumulation of cAMP in the rat ventricular heart muscle, thus improving circulation. We guess that ILG was probably the bioactive compound, which was thought to be related to the honey-roasting licorice invigoration of $q i$ and promotion of blood circulation.

Another bioactive compound of licorice, glycyrrhizin, was reported to have extremely low oral bioavailability [22, 23]. Glycyrrhizin was mainly absorbed as glycyrrhetinic acid after metabolism by intestinal bacteria [24]. Thus, only glycyrrhetinic acid was detected in rat plasma in this study. The $\mathrm{C}_{\max }$ and $\mathrm{AUC}_{0-24 \mathrm{~h}}$ of $\mathrm{GA}$ in the $25 \%$ honey-roasting group were higher than those in the raw group. Interestingly, the $\mathrm{C}_{\max }$ and $\mathrm{AUC}_{0-24 \mathrm{~h}}$ of $\mathrm{GA}$ were remarkably higher than the total of the five flavones. Additionally, GA has been reported to have a hepatoprotective effect [25] and modulate inflammatory markers [26]. Based on these results, we suggest that GA in licorice might be the key to the efficacy of honey-roasting for invigorating $q i$ and restoring pulse.

Furthermore, the $\mathrm{C}_{\max }$ and $\mathrm{AUC}_{0-24 \mathrm{~h}}$ of LQ, LG, and ILG between the $25 \%$ honey-roasting and $50 \%$ honey-roasting groups exhibited a great change. Moreover, compared with the raw licorice group, the $\mathrm{C}_{\max }$ of LA, LQ, and LG were $43.7 \%, 53.96 \%$, and $54.9 \%$ lower in the $50 \%$ honey-roasting group, respectively. There were no significant differences in the pharmacokinetic parameters for LA, LQ, LG, and ILG between the raw and 25\% honey-roasting groups. The most possible cause of these phenomena is that the quantity of honey affected the contents of bioactive compounds in licorice. Previous research has shown that the contents of LQ and LG in honey-roasting licorice decreased with the amount of honey added during the honey-roasting process [27]. In addition, the content of LQ is in accordance with the quality standard of licorice listed in the Chinese Pharmacopoeia Committee (2015). In conclusion, after licorice was processed with honey, the contents of flavones varied, which influenced the pharmacokinetic behavior of the flavones in rats fed honey-roasting licorice. Therefore, the amount of honey added during the honey-roasting process should be strictly controlled.

\section{Conclusions}

In this study, the comparison of the pharmacokinetic behaviors of licorice flavones indicated that the absorption of isoliquiritin was inhibited while that of isoliquiritigenin was promoted after the honey-roasting process. Additionally, the amount of honey added during the honey-roasting process influenced the pharmacokinetic parameters of the six compounds. These findings prove that honey-roasting process 


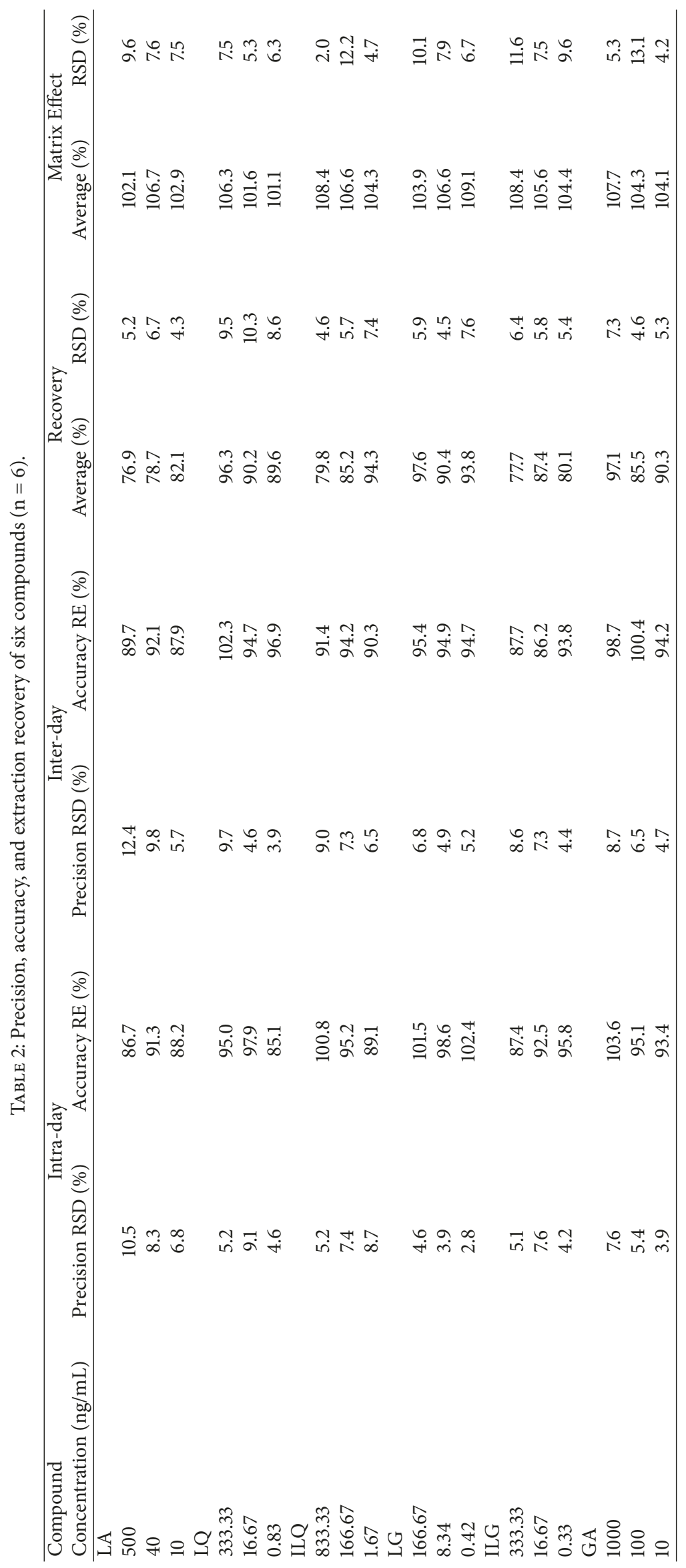




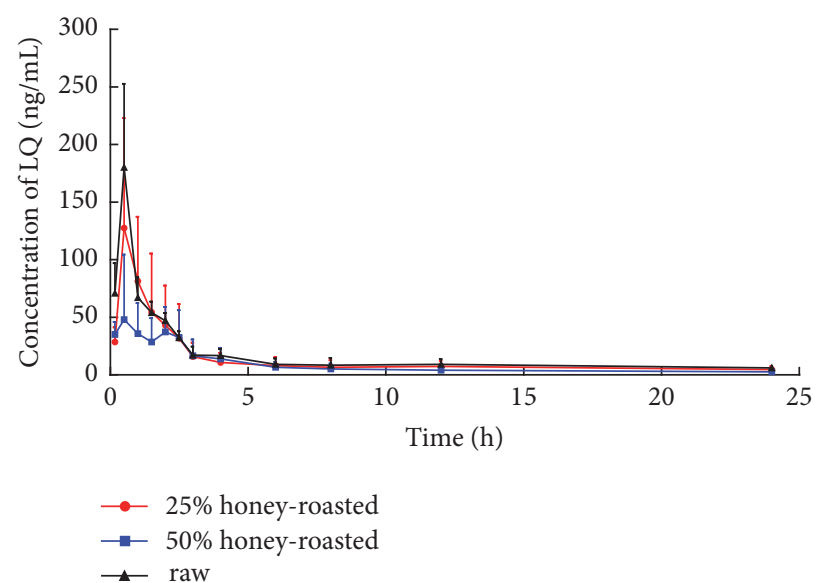

(a)

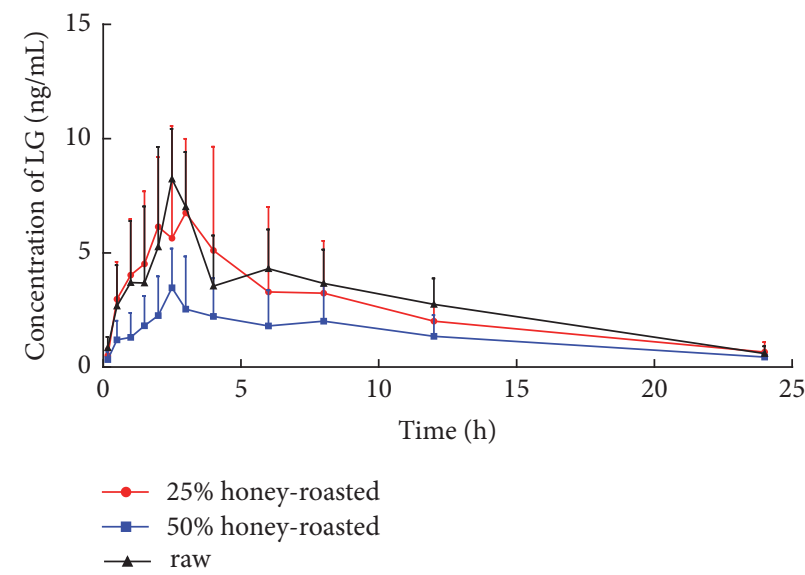

(c)

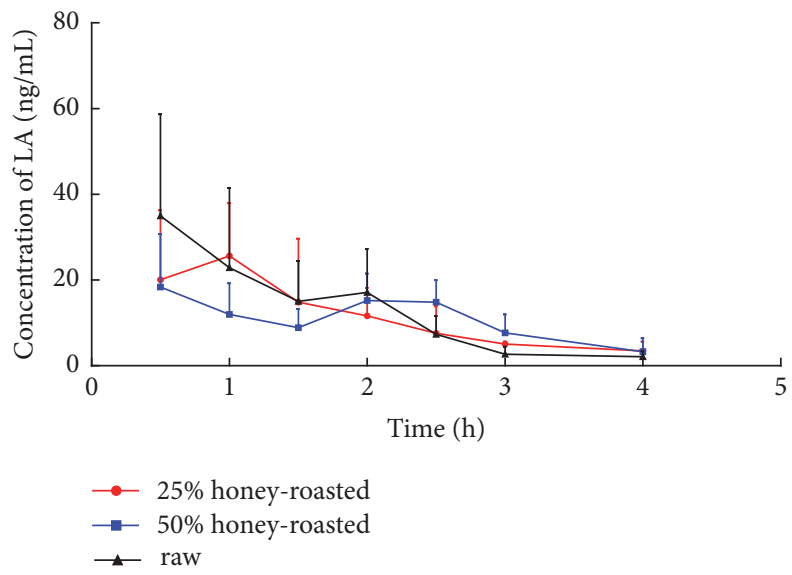

(e)

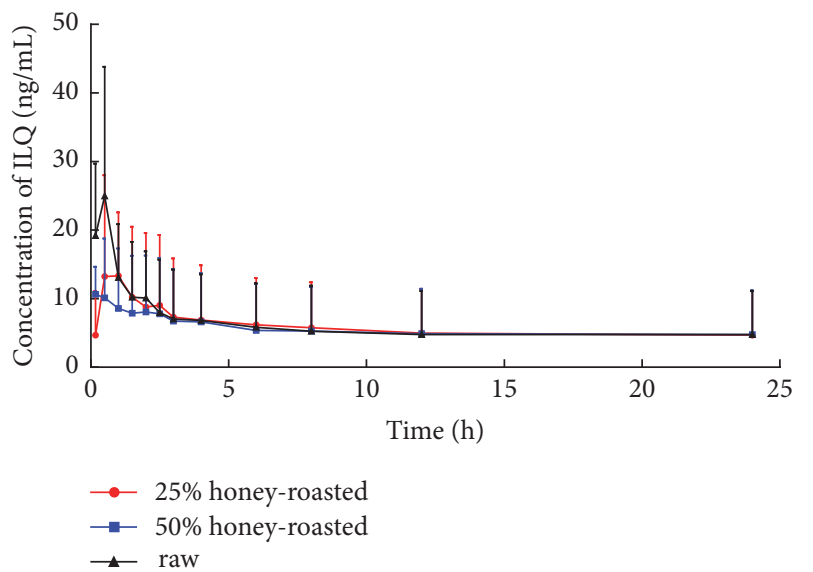

(b)

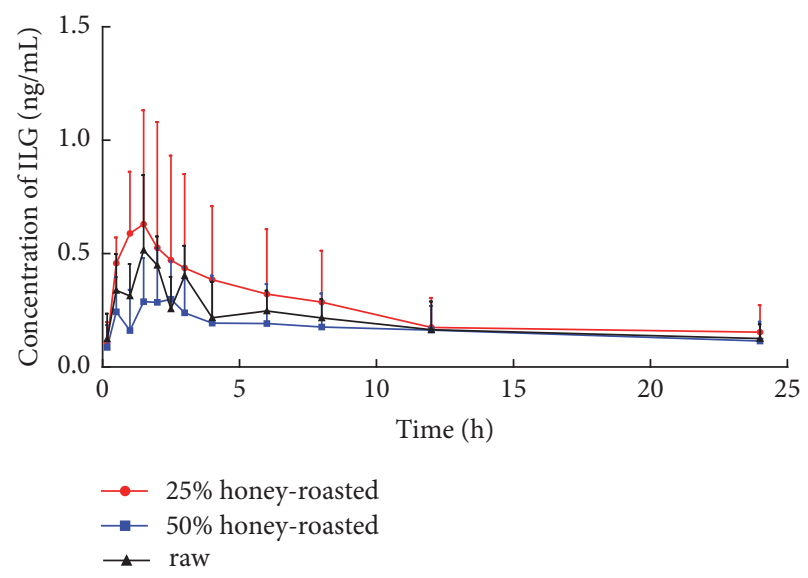

(d)

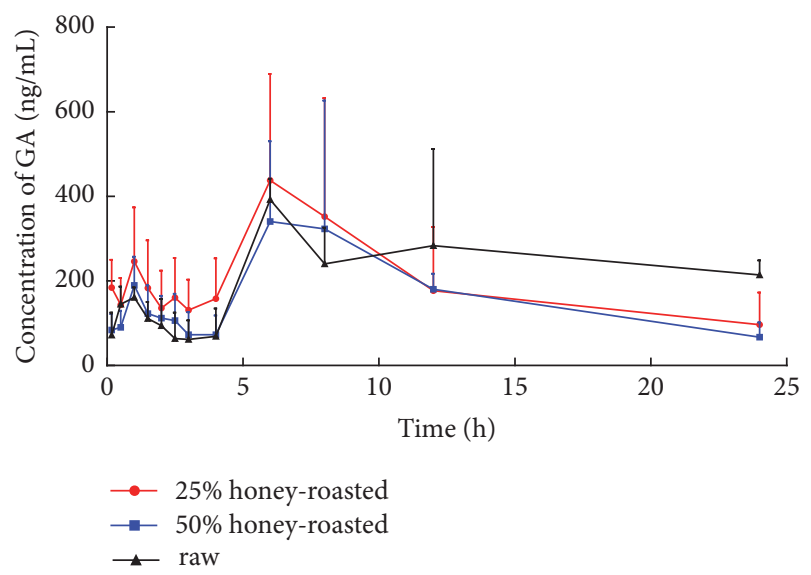

(f)

Figure 2: Plasma concentration-time profiles of LQ (a), ILQ (b), LG (c), ILG (d), LA (e), and GA (f) after oral administration water decoction of $25 \%$ honey-roasting licorice, $50 \%$ honey-roasting licorice, and raw licorice, respectively.

can influence the pharmacokinetic behaviors of bioactive compound in licorice and give one possible explanation of the phenomena that raw licorice is stronger at relieving cough, while honey-roasted licorice is better at invigorating $q i$ and restoring pulse.

\section{Data Availability}

This article provides the results of the statistical data, and the primary data could be requested from the corresponding author. 
TABLE 3: Stability of six compounds in rat plasma $(n=6)$.

\begin{tabular}{|c|c|c|c|c|c|}
\hline \multirow{2}{*}{ Compound } & \multirow{2}{*}{ Concentration $(\mathrm{ng} / \mathrm{mL})$} & \multicolumn{2}{|c|}{ At $4^{\circ} \mathrm{C}$ for $24 \mathrm{~h}$} & \multicolumn{2}{|c|}{ At $-80^{\circ} \mathrm{C}$ for 1 month } \\
\hline & & Average (\%) & RSD (\%) & Average (\%) & RSD (\%) \\
\hline \multirow[t]{3}{*}{ LA } & 500 & 98.3 & 4.9 & 95.3 & 8.7 \\
\hline & 40 & 92.4 & 8.6 & 93.7 & 9.4 \\
\hline & 10 & 97.3 & 4.8 & 93.2 & 3.8 \\
\hline \multirow[t]{3}{*}{ LQ } & 333.33 & 99.5 & 7.5 & 89.5 & 4.9 \\
\hline & 16.67 & 88.3 & 5.6 & 95.6 & 5.3 \\
\hline & 0.83 & 90.9 & 6.3 & 96.4 & 9.5 \\
\hline \multirow[t]{3}{*}{ ILQ } & 833.33 & 95.7 & 8.9 & 100.1 & 9.8 \\
\hline & 166.67 & 89.3 & 3.6 & 94.2 & 5.6 \\
\hline & 1.67 & 90.2 & 7.3 & 89.4 & 5.8 \\
\hline \multirow[t]{3}{*}{ LG } & 166.67 & 93.9 & 8.1 & 96.5 & 2.1 \\
\hline & 8.34 & 87.7 & 5.9 & 97.3 & 7.8 \\
\hline & 0.42 & 90.8 & 6.7 & 92.8 & 6.5 \\
\hline \multirow[t]{3}{*}{ ILG } & 333.33 & 93.1 & 7.8 & 87.6 & 8.2 \\
\hline & 16.67 & 96.4 & 8.9 & 85.3 & 9.1 \\
\hline & 0.33 & 95.7 & 12.3 & 94.7 & 7.5 \\
\hline \multirow[t]{3}{*}{ GA } & 1000 & 100.9 & 11.2 & 97.3 & 4.9 \\
\hline & 100 & 96.2 & 6.7 & 102.1 & 7.4 \\
\hline & 10 & 96.4 & 8.9 & 96.2 & 5.0 \\
\hline
\end{tabular}

TABle 4: Pharmacokinetic parameters for six compounds in rat plasma after oral administration of raw/honey-roasting licorice $(\mathrm{n}=5)$.

\begin{tabular}{|c|c|c|c|c|}
\hline Analytes & Group & $\mathrm{C}_{\max }(\mathrm{ng} / \mathrm{mL})$ & $\mathrm{T}_{\max }(\mathrm{h})$ & $\operatorname{AUC}_{0-24 \mathrm{~h}}(\mathrm{~h} \cdot \mathrm{ng} / \mathrm{mL})$ \\
\hline \multirow[t]{3}{*}{ LA } & $25 \%$ honey-roasting & $38.49 \pm 13.09$ & 0.8 & $64.77 \pm 17.97^{*}$ \\
\hline & $50 \%$ honey-roasting & $31.21 \pm 8.09^{*}$ & 0.9 & $56.30 \pm 14.34$ \\
\hline & Raw & $55.46 \pm 13.51$ & 0.7 & $82.31 \pm 19.00$ \\
\hline \multirow[t]{3}{*}{ LQ } & $25 \%$ honey-roasting & $202.93 \pm 54.12$ & 0.6 & $478.69 \pm 65.22$ \\
\hline & $50 \%$ honey-roasting & $87.93 \pm 8.08^{* \Delta}$ & 0.5 & $318.94 \pm 49.99^{* \Delta}$ \\
\hline & Raw & $191.00 \pm 80.23$ & 0.6 & $520.48 \pm 94.53$ \\
\hline \multirow[t]{3}{*}{ ILQ } & $25 \%$ honey-roasting & $24.80 \pm 3.63^{*}$ & 0.7 & $260.44 \pm 8.53$ \\
\hline & $50 \%$ honey-roasting & $20.59 \pm 5.82^{*}$ & 0.4 & $246.22 \pm 7.67^{\Delta}$ \\
\hline & Raw & $47.76 \pm 2.62$ & 0.4 & $257.39 \pm 19.28$ \\
\hline \multirow[t]{3}{*}{ LG } & $25 \%$ honey-roasting & $12.02 \pm 3.67$ & 2.3 & $85.36 \pm 14.70$ \\
\hline & $50 \%$ honey-roasting & $5.46 \pm 1.61^{* \Delta}$ & 2.5 & $47.74 \pm 8.03^{* \Delta}$ \\
\hline & Raw & $12.11 \pm 5.07$ & 2.4 & $84.29 \pm 33.71$ \\
\hline \multirow[t]{3}{*}{ ILG } & $25 \%$ honey-roasting & $1.12 \pm 0.25$ & 1.5 & $9.32 \pm 0.68^{*}$ \\
\hline & $50 \%$ honey-roasting & $0.56 \pm 0.12^{\Delta}$ & 1.8 & $6.13 \pm 0.80^{\Delta}$ \\
\hline & Raw & $0.75 \pm 0.28$ & 1.5 & $6.53 \pm 2.34$ \\
\hline \multirow[t]{3}{*}{ GA } & $25 \%$ honey-roasting & $650.93 \pm 199.95$ & 6.8 & $6995.30 \pm 1293.79$ \\
\hline & $50 \%$ honey-roasting & $607.78 \pm 277.70$ & 6.8 & $5177.10 \pm 2540.93$ \\
\hline & Raw & $571.98 \pm 311.21$ & 8.0 & $6979.29 \pm 4803.95$ \\
\hline
\end{tabular}

$* P<0.05$, compared with the raw group. $\Delta P<0.05$, compared with the $25 \%$ honey-roasting group. $\mathrm{n}$ : the number of rats.

\section{Conflicts of Interest}

The authors declare no conflicts of interest.

\section{Acknowledgments}

This work was supported by grants from National Natural Science Foundation of China. (no. 81173551 and no. 81274062).

\section{References}

[1] National Commission of Chinese Pharmacopoeia, Pharmacopoeia of People's Republic of China, vol. I, China Medical Science Press, Beijing, China, 2015.

[2] J.-K. Kim, S.-M. Oh, H.-S. Kwon, Y.-S. Oh, S. S. Lim, and H.-K. Shin, "Anti-inflammatory effect of roasted licorice extracts on lipopolysaccharide-induced inflammatory responses in murine 
macrophages," Biochemical and Biophysical Research Communications, vol. 345, no. 3, pp. 1215-1223, 2006.

[3] K. R. Kim, C. K. Jeong, K. K. Park et al., "Anti-inflammatory effects of licorice and roasted licorice extracts on TPA-induced acute inflammation and collagen-induced arthritis in mice," Journal of Biomedicine Biotechnology, vol. 2010, Article ID 709378, 2010.

[4] I.-K. Hwang, S.-S. Lim, K.-H. Choi et al., "Neuroprotective effects of roasted licorice, not raw form, on neuronal injury in gerbil hippocampus after transient forebrain ischemia," Acta Pharmacologica Sinica, vol. 27, no. 8, pp. 959-965, 2006.

[5] T. Majima, T. Yamada, E. Tega, H. Sakurai, I. Saiki, and T. Tani, "Pharmaceutical evaluation of liquorice before and after roasting in mice," Journal of Pharmacy and Pharmacology, vol. 56, no. 5, pp. 589-595, 2004.

[6] M. N. Asl and H. Hosseinzadeh, "Review of pharmacological effects of Glycyrrhiza sp. and its bioactive compounds," Phytotherapy Research, vol. 22, no. 6, pp. 709-724, 2008.

[7] Q. Zhang and M. Ye, "Chemical analysis of the Chinese herbal medicine Gan-Cao (licorice)," Journal of Chromatography A, vol. 1216, no. 11, pp. 1954-1969, 2009.

[8] J. Cheel, G. Onofre, D. Vokurkova, L. Tumova, and J. Neugebauerova, "Licorice infusion: Chemical profile and effects on the activation and the cell cycle progression of human lymphocytes," Pharmacognosy Magazine, vol. 6, pp. 26-33, 2010.

[9] T.-C. Kao, C.-H. Wu, and G.-C. Yen, "Bioactivity and potential health benefits of licorice," Journal of Agricultural and Food Chemistry, vol. 62, no. 3, pp. 542-553, 2014.

[10] W.-W. Huang, M.-Y. Wang, H.-M. Shi et al., "Comparative study of bioactive constituents in crude and processed Glycyrrhizae radix and their respective metabolic profiles in gastrointestinal tract in vitro by HPLC-DAD and HPLC-ESI/MS analyses," Archives of Pharmacal Research, vol. 35, no. 11, pp. 1945-1952, 2012.

[11] E. Gumpricht, R. Dahl, M. W. Devereaux, and R. J. Sokol, "Licorice compounds glycyrrhizin and $18 \beta$-glycyrrhetinic acid are potent modulators of bile acid-induced cytotoxicity in rat hepatocytes," The Journal of Biological Chemistry, vol. 280, no. 11, pp. 10556-10563, 2005.

[12] M. Michaelis, J. Geiler, P. Naczk et al., "Glycyrrhizin exerts antioxidative effects in $\mathrm{H} 5 \mathrm{~N} 1$ influenza A virus-infected cells and inhibits virus replication and pro-inflammatory gene expression," PLoS ONE, vol. 6, no. 5, Article ID e19705, 2011.

[13] Y. L. Zhang, M. Y. Wang, J. Y. Yang, and X. B. Li, "Research process of chemical constituents and pharmacological effects of baked licorice," Acta Universitatis Traditionis MedicalisSinensis Pharmacologiaeque Shanghai, vol. 3, pp. 99-102, 2015.

[14] M. Wang, M. Zhang, Q. Tang, and X. Li, "Influence of honey-roasting on the main pharmacological activities and the water-soluble active glycosides of licorice," African journal of traditional, complementary, and alternative medicines : AJTCAM/African Networks on Ethnomedicines, vol. 9, no. 2, pp. 189196, 2012.

[15] Y.-Q. Liu, M.-Y. Wang, H.-M. Shi, Q.-S. Sun, and X.-B. Li, "Determination of five active constituents in licorice and its processed products," Chinese Pharmaceutical Journal, vol. 43, no. 16, pp. 1268-1271, 2008.

[16] M. Zhang, M.-Y. Wang, Y.-Q. Liu, and X.-B. Li, "Changes of contents and decocted contents of main glycosides in glycyrrhizae radix et rhizoma under different processing conditions," Chinese Traditional and Herbal Drugs, vol. 42, no. 7, pp. 1305-1308, 2011.
[17] Y.-P. Wu, X.-S. Meng, Y.-R. Bao, and S. Wang, "Pharmacokinetic study of four flavones of Glycyrrhiza in rat plasma using HPLCMS," Journal of Ethnopharmacology, vol. 148, no. 1, pp. 266-270, 2013.

[18] J. Kamei, A. Saitoh, T. Asano et al., "Pharmacokinetic and pharmacodynamic profiles of the antitussive principles of Glycyrrhizae radix (licorice), a main component of the Kampo preparation Bakumondo-to (Mai-men-dong-tang)," European Journal of Pharmacology, vol. 507, no. 1-3, pp. 163-168, 2005.

[19] J. Kamei, R. Nakamura, H. Ichiki, and M. Kubo, "Antitussive principles of Glycyrrhizae radix, a main component of the Kampo preparations Bakumondo-to (Mai-men-dong-tang)," European Journal of Pharmacology, vol. 469, no. 1-3, pp. 159-163, 2003.

[20] M. Tawata, K. Aida, T. Noguchi et al., "Anti-platelet action of isoliquiritigenin, an aldose reductase inhibitor in licorice," European Journal of Pharmacology, vol. 212, no. 1, pp. 87-92, 1992.

[21] J. W. Wegener and H. Nawrath, "Cardiac effects of isoliquiritigenin," European Journal of Pharmacology, vol. 326, no. 1, pp. 37-44, 1997.

[22] M. A. Raggi, F. Maffei, F. Bugamelli, and G. Cantelli Forti, "Bioavailability of glycyrrhizin and licorice extract in rat and human plasma as detected by a HPLC method," Die Pharmazie, vol. 49, no. 4, pp. 269-272, 1994.

[23] Y. Yamamura, J. Kawakami, T. Santa et al., "Pharmacokinetic profile of glycyrrhizin in healthy volunteers by a new high-performance liquid chromatographic method," Journal of Pharmaceutical Sciences, vol. 81, no. 10, pp. 1042-1046, 1992.

[24] T. Akao, T. Hayashi, K. Kobashi et al., "Intestinal bacterial hydrolysis is indispensable to absorption of $18 \beta$-glycyrrhetic acid after oral administration of glycyrrhizin in rats," Journal of Pharmacy and Pharmacology, vol. 46, no. 2, pp. 135-137, 1994.

[25] T. Moro, Y. Shimoyama, M. Kushida et al., "Glycyrrhizin and its metabolite inhibit Smad3-mediated type I collagen gene transcription and suppress experimental murine liver fibrosis," Life Sciences, vol. 83, no. 15-16, pp. 531-539, 2008.

[26] S. K. Hasan, A. Siddiqi, S. Nafees et al., "Chemopreventive effect of $18 \beta$-glycyrrhetinic acid via modulation of inflammatory markers and induction of apoptosis in human hepatoma cell line (HepG2)," Molecular and Cellular Biochemistry, vol. 416, no. 1-2, pp. 169-177, 2016.

[27] Y. Q. Liu, The Effects of Licorice Compounds and Its Pharmcology by Honey-Roasting Process, Shenyang Pharmaceutical University, 2008. 


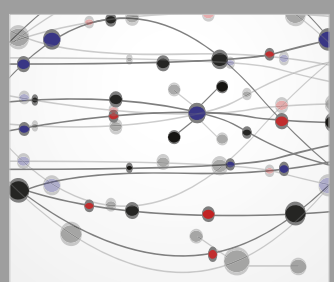

The Scientific World Journal
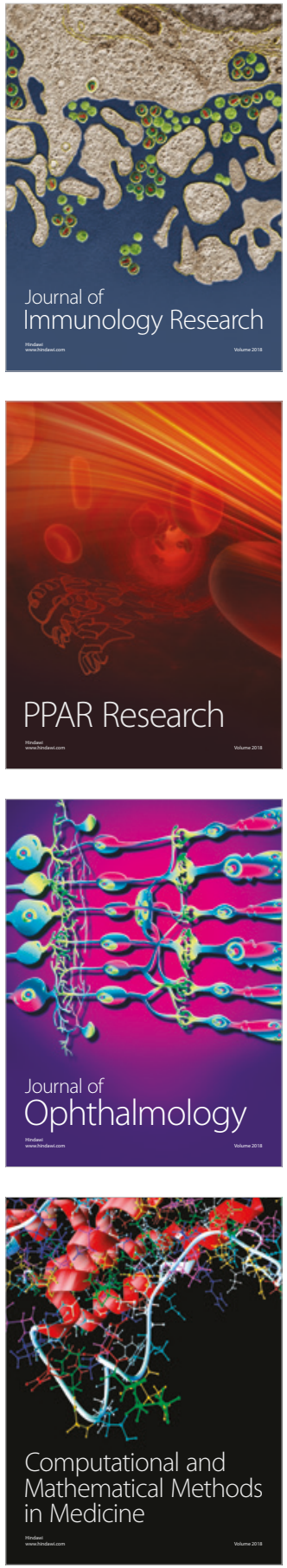

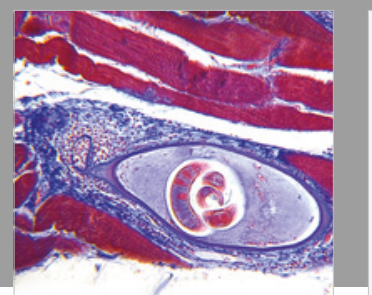

Gastroenterology Research and Practice

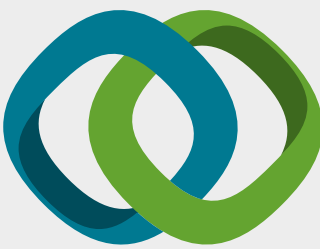

\section{Hindawi}

Submit your manuscripts at

www.hindawi.com
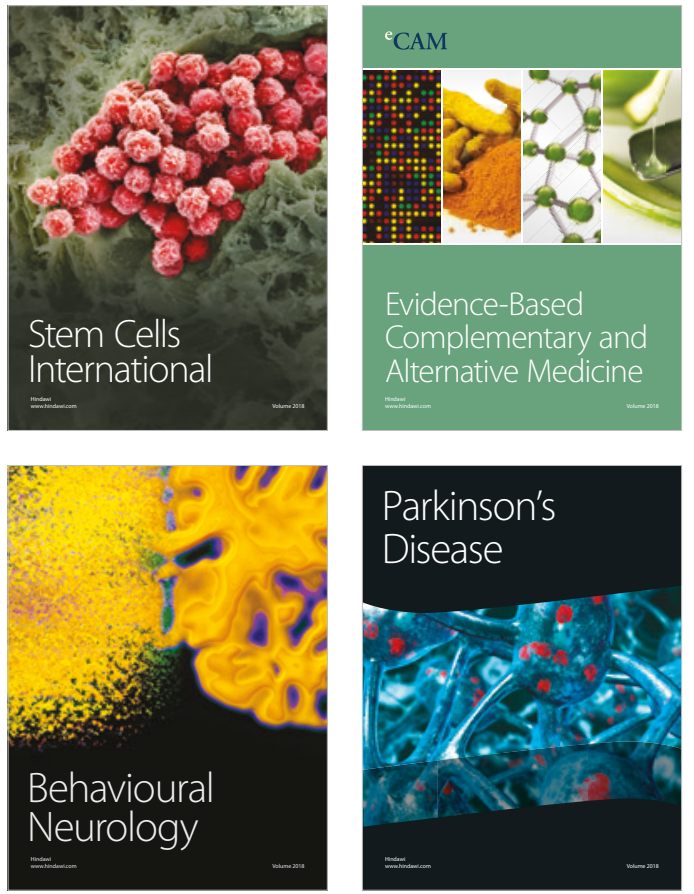

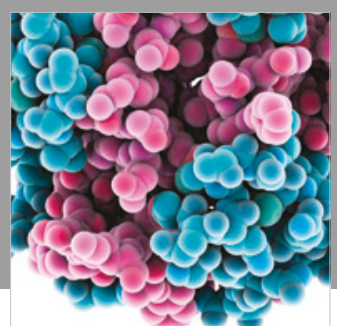

ournal of

Diabetes Research

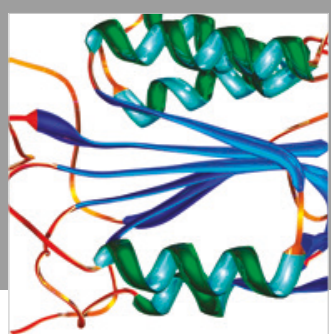

Disease Markers
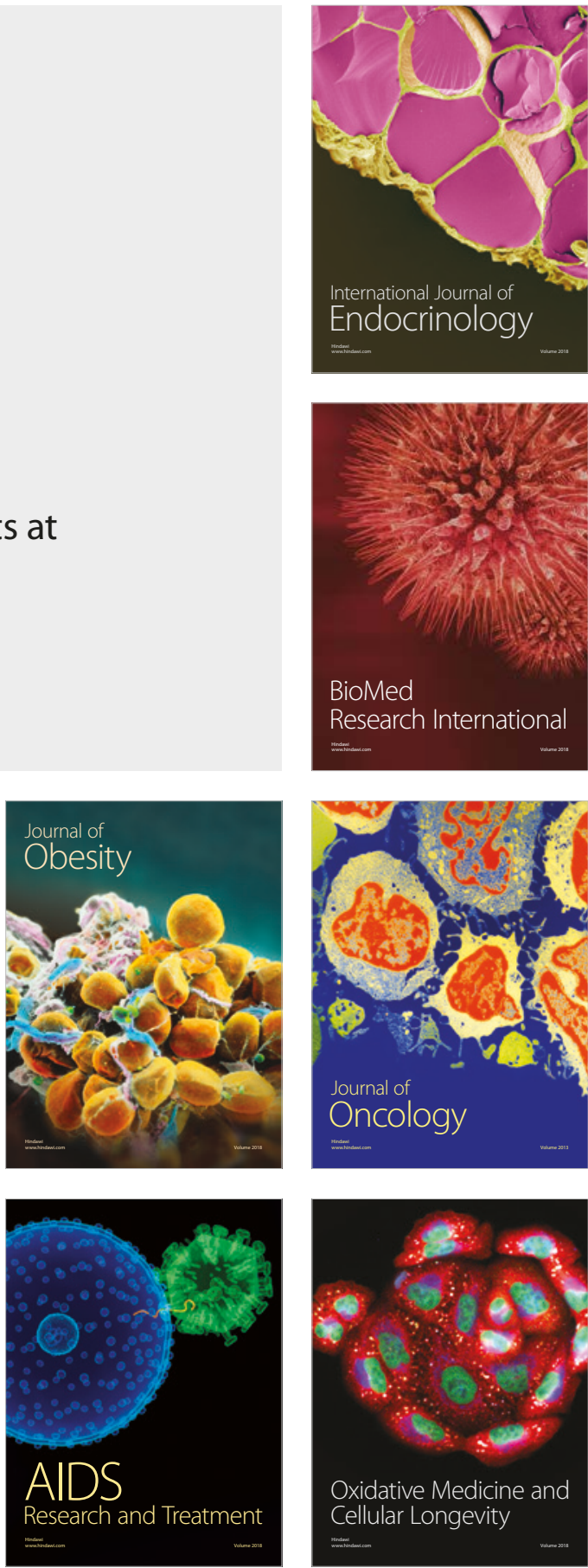